\title{
Response of Young Olive Plants (Olea europaea) to Phosphorus Application
}

\author{
María José Jiménez-Moreno and Ricardo Fernández-Escobar ${ }^{1}$ \\ Departamento de Agronomía, Campus Universitario de Rabanales, \\ Universidad de Córdoba, Edificio C 4, Carretera Madrid-Cádiz, km 396, \\ 14071 Córdoba, Spain
}

Additional index words. phosphorus nutrition, phosphorus uptake efficiency, phosphorus excess, $\mathrm{Zn}$ deficiency

\begin{abstract}
Mist-rooted 'Picual' olive cuttings growing in 1.1-L pots containing a mixture of washed sand and perlite were used to induce symptoms of phosphorus $(P)$ deficiency and toxicity and to determine the nutritional status to which these symptoms occur. Plants were growing in a growth chamber at $25^{\circ} \mathrm{C}$ day/15 ${ }^{\circ} \mathrm{C}$ night with a 14 -hour photoperiod. From late spring to the autumn, plants were placed in a shade house protected from the rain. In the first experiment, plants received the application of $0,100,200$, or $400 \mathrm{ppm} P$, and in the second experiment, 0, 12.5, 25, 50, 100, or $200 \mathrm{ppm} P$. Shoot growth was measured weekly and leaf samples were collected at different dates to determine $P$ concentration. At the end of each experiment, plants were harvested and $P$ was determined to obtain the $P$ uptake by the plants. Phosphorus uptake efficiency (PUE) was estimated as $P U E=(P$ uptake $/ P$ applied $) \times 100 . P$ content increased in plants with the amount of $P$ applied, and accumulated mainly in the roots. Vegetative growth showed a quadratic response, indicating a reduction of growth at the lowers and highest doses of $P$ application. Leaf $P$ concentration below or above which shoot growth was reduced was $0.11 \%$ to $0.13 \%$. Symptoms of $P$ deficiency and toxicity were observed in only a few plants. Leaf $P$ concentration of deficient plants was $0.025 \%$, and that of toxicity $0.21 \%$. Toxicity symptoms were similar to that of zinc $(\mathrm{Zn})$ deficiency. PUE was very low, $1.34 \%$ to $4.45 \%$, suggesting the low $P$ requirements of the olive.
\end{abstract}

The olive (Olea europaea L.) is an evergreen tree that has been cultivated from ancient times. It occupies a surface of around 10 million hectares all over the world, of which only around $10 \%$ is irrigated. It is a species adapted to adverse conditions, grown mainly on dryland areas and calcareous soils around the Mediterranean Basin. Under these conditions, potassium represents the main nutritional problem of olive trees (Restrepo-Diaz et al., 2008). Little is known on $\mathrm{P}$ nutrition in the olive, since no growth response to $\mathrm{P}$ has been observed under field conditions (Fernández-Escobar, 2008a; Hartmann et al., 1966).

However, $\mathrm{P}$ is a plant macronutrient that plays an important role in many plant physiological processes. It is a structural constituent of macromolecules such as nucleic acids, and forms part of nucleoproteins, phospholipids, and a large number of enzymes involved in energy processes. These are directly correlated with the development of the plant and, particularly, its root system (Rausch and Bucher, 2002; Schachtman et al., 1998). Insufficient availability or extremely high levels of

\footnotetext{
Received for publication 16 June 2016. Accepted for publication 22 July 2016.

This research was supported by the Ministerio de Ciencia e Innovación, Spain, Project No. AGL2011-25752; Junta de Andalucía, Spain, Project of Excellence P11-AGR-7835; and European Regional Development Fund (ERDF).

${ }^{1}$ Corresponding author. E-mail: rfernandezescobar@ uco.es.
}

$\mathrm{P}$ acquisition and utilization by woody plants include mycorrhizal symbioses (Smith and Read, 2008), and downregulation of P uptake (de Campos et al., 2013). Since P is easily reused in woody plants, severe $\mathrm{P}$ deficiency to produce symptoms in leaves is rare in mature trees (Shear and Faust, 1980). In olive orchards is also rare to find leaf $P$ concentrations reaching the critical value for deficiency (Fernández-Escobar, 2008a). Also, P removed in olive trees by yield and pruning is very low $\left(6.9 \mathrm{~kg} \cdot \mathrm{ha}^{-1} \cdot\right.$ year $\left.^{-1}\right)$ compared with other macronutrients (Fernández-Escobar et al., 2015). This may explain the lack of response to $\mathrm{P}$ fertilization of olive trees growing under field conditions (Hartmann et al., 1966). Nevertheless, $\mathrm{P}$ is a nutrient normally applied through fertilization in olive orchards (FernándezEscobar, 2008b).

Neither $\mathrm{P}$ deficiency nor $\mathrm{P}$ toxicity has been observed in olive grown under field conditions. However, it might be interesting to know the symptomatology associated with these nutritional disorders and the nutritional status of the olive to which these symptoms occur. Thus, the objective of this work was to study the response of young olive plants to $\mathrm{P}$ application, to determine the critical values which may cause deficiency or toxicity symptoms in these plants to a better understanding of $\mathrm{P}$ nutrition, and also to determine phosphorus uptake efficiency (PUE)

\section{Materials and Methods}

P significantly affect plant growth and development (Zeng et al., 2014). Furthermore, the intricate mechanisms involved in maintaining phosphate $(\mathrm{Pi})$ homeostasis reflect the complexity of $\mathrm{Pi}$ acquisition and translocation in plants (Raghothama, 1999).

Phosphorus is a limiting factor for crop yield on more than $30 \%$ of the world's arable land (Vance et al., 2003), and its concentration in soils is low compared with other macronutrients (Bieleski, 1973). More than $80 \%$ of $\mathrm{P}$ becomes immobile and unavailable for plant uptake because of adsorption, precipitation, or conversion to the organic form (Holford, 1997). In addition, the movement of $\mathrm{P}$ in soils takes place mainly by diffusion and the rate of this process is slow (Schachtman et al., 1998). Therefore, applications of chemical $\mathrm{P}$ fertilizers are needed to improve crop growth and yield in many agricultural systems (Shen et al., 2011). Because of the limited and nonrenewable $\mathrm{P}$ resources for fertilizer production, $\mathrm{P}$ fertilizer applications will be restricted within the next $60-90$ years. Consequently, the increase in crop $\mathrm{P}$ efficiency is currently receiving more attention (Thornton et al., 2014).

Phosphorus uptake, cycling, and use efficiency has been investigated intensively with annual plants, but little is known in perennial, woody plants (Rennenberg and Herschbach, 2013). In deciduous trees, $P$ is remobilized from senescing leaves in autumn and stored in other tissues for reuse in the following spring (Barrelet et al., 2006; Eschrich et al., 1988; Kurita et al., 2014). Other strategies for
Plant material and growth conditions. Mist-rooted 'Picual' olive cuttings were grown in $0.7-\mathrm{L}$ pots filled with perlite during 8 to 12 months of acclimation, depending on the experiment, and then transferred to $1.1-\mathrm{L}$ pots containing a mixture of washed sand and perlite ( $2: 1$ by volume). After acclimatization, plants were pruned to a single shoot and received the treatments. Two different experiments were carried out with these olive plants growing in a growth chamber under controlled conditions of $25 / 15^{\circ} \mathrm{C}$ day/night temperature, $60 \%$ relative humidity, and a photoperiod of $14 \mathrm{~h}$. From late spring to the autumn, plants were placed in a shade house protected from rain with a transparent roof-like structure. Plants were watered one or two times a week, depending on the period, with 30 or $100 \mathrm{~mL}$ water per pot, and monthly with a nutrient solution without $\mathrm{P}$ to prevent nutritional deficiencies. This solution was composed of $2.5 \mathrm{~mm} \mathrm{Ca}\left(\mathrm{NO}_{3}\right)_{2}, 2.5 \mathrm{~mm}$ $\mathrm{KNO}_{3}, 1.0 \mathrm{~mm} \mathrm{MgSO}_{4}, 12.5 \mu \mathrm{M} \mathrm{H}_{3} \mathrm{BO}_{3}$, $1.0 \mu \mathrm{M} \mathrm{ZnSO}_{4}, 0.2 \mu \mathrm{M}\left(\mathrm{NH}_{4}\right)_{6} \mathrm{Mo}_{7} \mathrm{O}_{24}, 10 \mu \mathrm{M}$ Fe-ethylenediamine-di-o-hydroxy-phenylacetic acid, and $0.5 \mathrm{~mm} \mathrm{KCl}$.

The first experiment was arranged in a completely randomized design with four treatments and seven plant replications. The treatments consisted on the application of $0,100,200$, or $400 \mathrm{ppm}$ P. Orthophosphoric acid $\left(\mathrm{H}_{3} \mathrm{PO}_{4}\right)$ was used as $\mathrm{P}$ source. One application of $\mathrm{P}$ solution per pot was applied weekly, alternating with an application of water. This experiment lasted for 5 months. The second experiment was similar to the 
Table 1. Phosphorus (P) content in leaf, stem, roots, and total plant according to the $\mathrm{P}$ applied.

\begin{tabular}{|c|c|c|c|c|c|c|c|c|}
\hline \multirow{2}{*}{$\begin{array}{l}\text { P applied } \\
\text { (ppm) }\end{array}$} & \multicolumn{8}{|c|}{ P content (mg) } \\
\hline & \multicolumn{2}{|c|}{ Leaves } & \multicolumn{2}{|c|}{ Stems } & \multicolumn{2}{|c|}{ Roots } & \multicolumn{2}{|c|}{ Total } \\
\hline 0 & 0.41 & 0.19 & 0.18 & 0.11 & 0.36 & 0.25 & 0.95 & 0.85 \\
\hline 25 & - & 0.75 & - & 0.23 & - & 0.75 & - & 2.71 \\
\hline 50 & - & 1.40 & - & 0.50 & - & 2.75 & - & 6.55 \\
\hline 100 & 3.34 & 1.21 & 1.56 & 0.52 & 3.56 & 4.05 & 8.46 & 7.51 \\
\hline 200 & 3.96 & 1.00 & 2.05 & 0.43 & 6.16 & 5.90 & 12.16 & 8.75 \\
\hline $\mathrm{CV}^{\mathrm{y}}$ & 24.0 & 52.2 & 43.9 & 45.6 & 31.9 & 36.7 & 24.5 & 29.1 \\
\hline
\end{tabular}

$\mathrm{z}^{*},{ }^{* *},{ }^{* * *}$ Significant at $P \leq 0.05,0.01$, or 0.001 , respectively; $\mathrm{L}=$ linear; $\mathrm{Q}=$ quadratic.

${ }^{\mathrm{y}}$ Coefficient of variation.
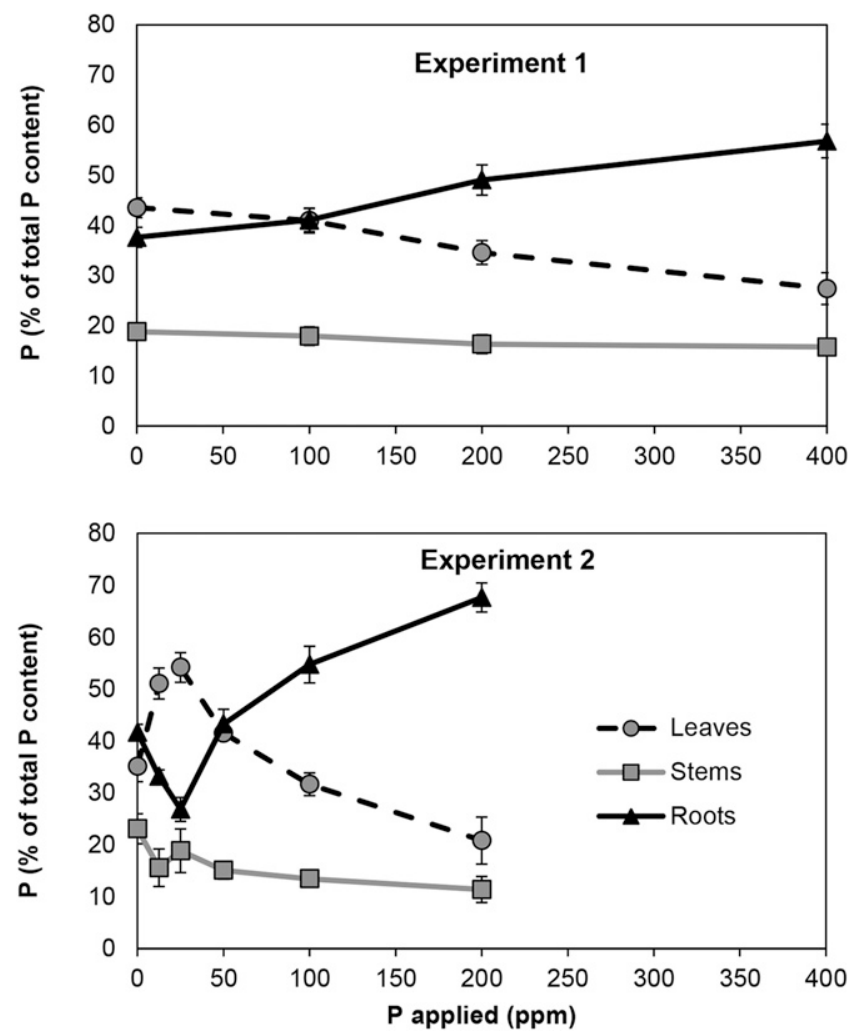

Fig. 1. Phosphorus (P) partitioning into olive trees related to the amount of $\mathrm{P}$ applied. Vertical bars represent the standard error of the means.

first one, but the treatments consisted on the application of $0,12.5,25,50,100$, or 200 ppm $\mathrm{P}$ and nine replications, and lasted for 6 months.

Growth measurements and $P$ and $Z n$ determination. Total vegetative growth was measured weekly on each experiment. Threemonth-old, fully expanded leaves were collected at different dates to determine $\mathrm{P}$ concentration. At the end of both experiments, plants were harvested and leaves, stems, and roots were removed separately from each plant, washed with distilled water, dried at $80^{\circ} \mathrm{C}$ for $72 \mathrm{~h}$, ground, and stored in an oven at $60{ }^{\circ} \mathrm{C}$ until analysis. The stored samples were ashed in a muffle furnace at $600^{\circ} \mathrm{C}$ for $12 \mathrm{~h}$ and dissolved in $0.1 \mathrm{~N} \mathrm{HCl}$. Phosphorus was determined by colorimetry using the colorimetric method described by Murphy and Riley (1962). Zn was measured using an atomic absorption spectrophotometer, PerkinElmer 1.100 B (PerkinElmer, Shelton, CT).

PUE was estimated according to the following formula:

$$
\mathrm{PUE}=\left(\frac{\mathrm{P} \text { uptake }}{\mathrm{P} \text { applied }}\right) \times 100
$$

where

$$
\begin{aligned}
\mathrm{P} \text { uptake }= & \mathrm{P} \text { in total plant } \\
& -\mathrm{P} \text { in plant with } 0 \mathrm{ppm} \mathrm{P}
\end{aligned}
$$

\section{$\mathrm{P}$ applied $=\mathrm{P}$ applied as fertilizer}

Statistical analyses. Analyses of variance and regression analyses were performed on the data using the statistical program Statistic Version 9.0 (Analytical Software, Tallahassee, FL). All percentage values were transformed using the arcsin of the square root before analysis. Where a significant $F$ was observed in the analysis of variance, mean separation between treatments was obtained by polynomial contrasts for quantitative factors.

\section{Results}

Influence of the amount of $P$ applied on $P$ content in the plant and on vegetative growth. Phosphorus content increased in leaves, stems, and roots, and also in the total plant, with increasing the amount of $\mathrm{P}$ applied (Table 1). Phosphorus accumulated mainly in the roots, followed by the leaves and stems. When data are expressed as percent of $\mathrm{P}$ content in each organ of the plant, the results showed that the proportion of $\mathrm{P}$ increased in the root with increasing the amount of $\mathrm{P}$ applied, whereas the proportion of $\mathrm{P}$ decreased in the leaves. No changes were observed in the stems (Fig. 1).

The accumulated vegetative growth showed a quadratic response to $\mathrm{P}$ application $\left(R^{2}=\right.$ 0.98 for Expt. 1 and $R^{2}=0.90$ for Expt. 2), indicating a reduction in shoot growth when the amount of $\mathrm{P}$ applied was lower or higher than 200 or 100 ppm in Expts. 1 and 2, respectively (Fig. 2). Leaf $\mathrm{P}$ concentration also showed a quadratic response $\left(R^{2}=0.98\right.$ for Expt. 1 and $R^{2}=0.97$ for Expt. 2) with the amount of $\mathrm{P}$ applied, but with a tendency to be asymptotic. At the points of higher growth, leaf $\mathrm{P}$ concentrations were $0.11 \%$ and $0.13 \%$, respectively. The reduction in vegetative growth at the lowest doses of $\mathrm{P}$ could be explained because of the low $\mathrm{P}$ availability for plants, as shown in Table 1, and the reduction at the highest doses could indicate toxicity effects. In both cases, the olive plants showed symptoms of $\mathrm{P}$ deficiency or P toxicity in leaves (Fig. 3). Deficiency symptoms were observed in only a few plants of the 0 ppm $P$ treatment of Expt. 1 at the end of the experiment. They showed apical chlorosis that turns progressively red and purple, and finally the petioles collapsed and the leaves fall. Leaf $\mathrm{P}$ concentration in these plants was $0.025 \%$. Symptoms of $\mathrm{P}$ excess were observed in plants of Expt. 2 receiving 100 or $200 \mathrm{ppm} \mathrm{P}$, showing leaves which turned yellowish with the veins and tissues surrounding the veins green, and finally fall. Leaf $\mathrm{P}$ concentration in these plants was $0.21 \%$. These symptoms of $\mathrm{P}$ excess are 

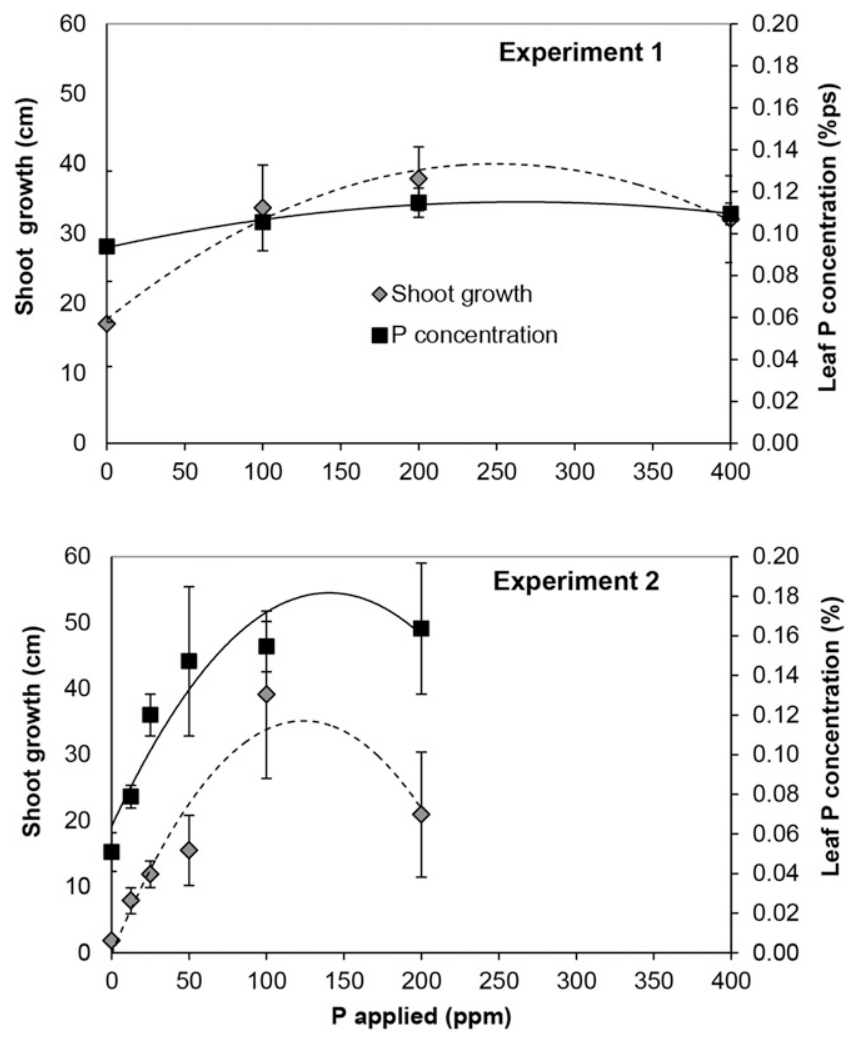

Fig. 2. Accumulated vegetative growth and leaf phosphorus $(\mathrm{P})$ concentration according to the $\mathrm{P}$ applied Vertical bars represent the standard error of the means.

A

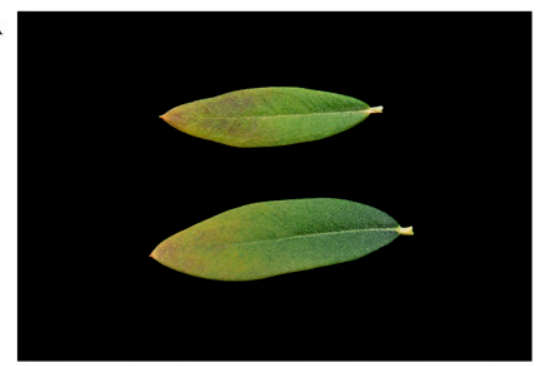

B

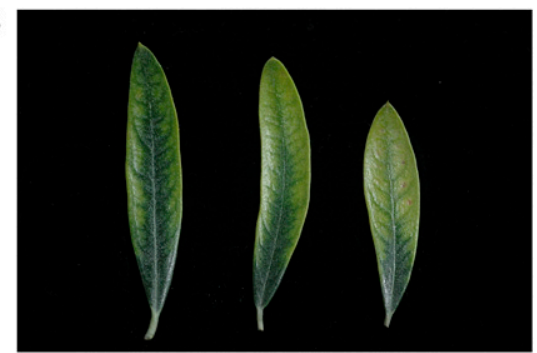

Fig. 3. (A) Phosphorus (P) deficiency symptoms in olive leaves and (B) P toxicity symptoms in olive leaves, similar to symptoms of zinc deficiency.

similar to that of $\mathrm{Zn}$ deficiency. In fact, leaf $\mathrm{Zn}$ concentration in leaves of the control plants without $\mathrm{P}$ application was $24.5 \mathrm{ppm}$, whereas leaf $\mathrm{Zn}$ concentration of plants showing symptoms was 5.34 and $11.2 \mathrm{ppm}$ in plants receiving 100 or $200 \mathrm{ppm} P$, respectively.

$P U E$. PUE increased slightly until $50 \mathrm{ppm}$ of $\mathrm{P}$ applied, and then decreased with the amount of $\mathrm{P}$ applied, reaching a minimum of $1.34 \%$ at 400 ppm P applied in Expt. 1 (Fig. 4).
The maximum PUE value was $4.45 \%$ at 50 ppm $\mathrm{P}$ in Expt. 2.

\section{Discussion}

Phosphorus is an important element in the fertilization program of many crops, but little attention has been paid by scientists to $\mathrm{P}$ nutrition in olive, as also occurs in other fruit tree species. This is because no growth response to $\mathrm{P}$ has been observed under field conditions (Fernández-Escobar, 2008a; Hartmann et al., 1966), since it is easily reused by woody plants (Barrelet et al., 2006; Eschrich et al., 1988; Kurita et al., 2014) and P removal by yield and pruning is very low compared with other macronutrients (Fernández-Escobar et al., 2015). Consequently, there have been no cases of $\mathrm{P}$ deficiency reported with field-grown olive trees (Hartmann et al., 1966). Deficiency symptoms have been induced only in young plants grown under an inert substrate. The only reference for olives was reported by Hartmann and Brown (1953) working with olives plants grown under sand culture. They found deficiency symptoms after 2 years without added $\mathrm{P}, 1$ year after cessation of shoot growth. However, they observed smaller leaves than the control but not the typical purple tones in leaves from P-deficient plants. At this moment, leaf $\mathrm{P}$ concentration dropped from $0.18 \%$ to $0.03 \%$. Our results are in agreement with this work, since deficient symptoms were observed in plants with a $\mathrm{P}$ level of $0.025 \%$. These symptoms, typical of $\mathrm{P}$ deficiencies as described in the above section, were observed only in a few plants of one of the experiments, but not in the other, 5 months after the initiation of treatments and 16 months after control plants were grown without added P. It should be noted that in a preliminary experiment no symptoms were observed after 2 years without P supply (data not shown). Very young, mistrooted olive plants were necessary in this study to induce symptoms of $\mathrm{P}$ deficiency and, even so, the symptomatology was not induced in all plants. These results indicate the difficulty to induce deficiency symptoms even in young olive plants. A decrease of growth was observed before the appearance of symptoms, at leaf $\mathrm{P}$ concentrations below $0.11 \%$ to $0.13 \%$. These levels are within the sufficiency range for the olive, although lower P levels are usually found in mature trees grown under field conditions without $P$ disorders (FernándezEscobar, 2008a; Hartmann et al., 1966). Anyway, it is very rare to reach in orchards the leaf $\mathrm{P}$ concentration obtained in this work for deficiency.

Phosphorus toxicity has not been reported in olive and is rare in other fruit trees. However, the species adapted to low-nutrient environments, as the Proteaceae, develop foliar symptoms of $\mathrm{P}$ toxicity when fertilized with $\mathrm{P}$ (Shane et al., 2004). This situation occurs when $\mathrm{P}$ uptake exceeds the storage capacity of root and stem tissues and $\mathrm{P}$ accumulates in leaves. In our work, a reduction of shoot growth was observed at the higher amounts of $\mathrm{P}$ applied in the second experiment together with the appearance of toxicity symptoms. Leaf $\mathrm{P}$ concentration in the symptomatic plants was around $0.21 \%$, double than the established sufficiency range of $0.1 \%$. Although in nature this is difficult to occur, it is possible that excess $\mathrm{P}$ in leaves in our experiment could be due to the limited capacity to store $\mathrm{P}$ in the root and stem tissues of the very young plants, leading to symptoms of $\mathrm{P}$ toxicity as described by Shane et al. (2004). This might also explain that very young trees usually have higher leaf $\mathrm{P}$ concentrations than mature trees. Also, the sufficiency range of $0.1 \%$ to $0.3 \%$ reported for $\mathrm{P}$ (Beutel et al., 1983) could be questioned since symptoms of $\mathrm{P}$ excess has been observed at leaf $P$ concentration of $0.21 \%$.

Excess $\mathrm{P}$ is usually expressed as the antagonism with other mineral nutrients such as Zn, Manganese, and other micronutrients (Marschner, 2012; Safaya, 1976; Shane et al., 2004). In this work, the symptoms of $P$ toxicity were similar to those found in $\mathrm{Zn}$ deficiency in the olive (Fernández-Escobar et al., 2016), probably due to an antagonism with $\mathrm{P}$ excess since leaf $\mathrm{Zn}$ concentration in symptomatic plants were lower than in control plants. High $\mathrm{P}$ concentration in plant tissue seems to decrease the physiological availability of $\mathrm{Zn}$ (Cakmak and Marschner, 1987), although the bases of this interaction are not well understood (Kisko et al., 2015).

PUE increased at low P supply, but then decreased with increasing $\mathrm{P}$ application, as expected. This pattern is similar to other nutrients as nitrogen in fruit tree species (Weinbaum et al., 1992). But in the present work, we found that PUE was very low, particularly compared with nitrogen uptake 

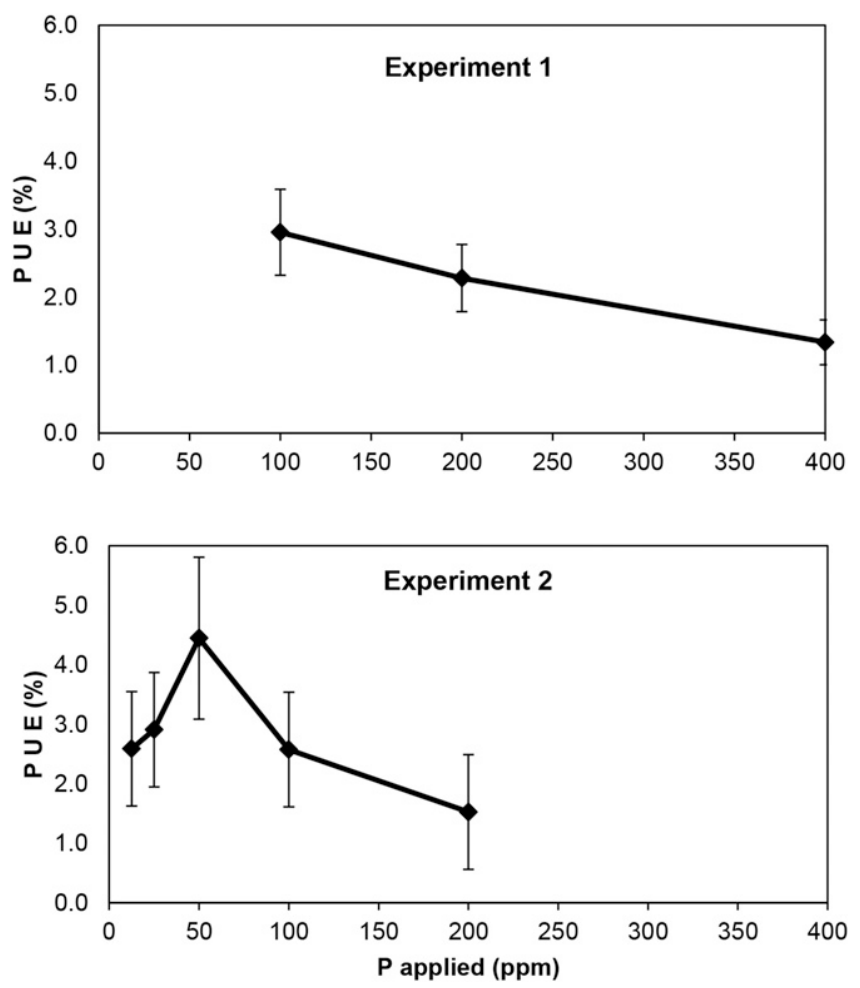

Fig. 4. Phosphorus uptake efficiency (PUE) related to the amount of phosphorus applied. Vertical bars represent the standard error of the means.

efficiency (NUE) in olive plants under similar growing conditions (Fernández-Escobar et al., 2014). NUE also depends on the nutritional status, being lower in well-nourished plants. The low PUE obtained in this work could be a consequence of the ability of the woody perennial plants to reuse $\mathrm{P}$ and to the low $\mathrm{P}$ removal, as mentioned above, suggesting the low $\mathrm{P}$ requirements of these plants. This also could explain the lack of response to P fertilization under field conditions (Hartmann et al., 1966). This is a very interesting point taking into account that the reserves of phosphate rock, the main source of $\mathrm{P}$ fertilizers, are finite and that at the current rate of use of $P$ fertilizers and the expected increase in the demand, this resource could disappear within a century (Dawson and Hilton, 2011; Gilbert, 2009). A more efficient use in agriculture, among other measures, could contribute to minimize this problem (Cordell et al., 2009). In this sense, a more sustainable and responsible use of $\mathrm{P}$ fertilizers in olive growing, and probably in other woody plants, is required. Applying P fertilizers only when there are proofs that it is needed to assure a normal growth and productivity may reduce $P$ application, which could be available to other crops with greater needs.

\section{Literature Cited}

Barrelet, T., A. Ulrich, H. Rennenberg, and U. Krähenbühl. 2006. Seasonal profiles of sulphur, phosphorus and potassium in Norway spruce wood. Plant Biol. 8:462-469.

Bieleski, R.L. 1973. Phosphate pools, phosphate transport and phosphate availability. Annu. Rev. Plant Physiol. 24:225-252.

Beutel, J., K. Uriu, and O. Lilleland. 1983. Leaf analysis for California deciduous fruits, p. 15-17. In: H.M. Reisenauer (ed.). Soil and plant tissue testing in California. University of California, Bull. 1879.

Cakmak, I. and H. Marschner. 1987. Mechanism of phosphorus-induced zinc deficiency in cotton. III. Changes in physiological availability of zinc in plants. Physiol. Plant. 70:13-20.

Cordell, D., J.O. Drangert, and S. White. 2009. The story of phosphorus: Global food security and food for thought. Glob. Environ. Change 19:292-305.

Dawson, C.J. and J. Hilton. 2011. Fertiliser availability in a resource-limited world: Production and recycling of nitrogen and phosphorus. Food Policy 36:S14-S22.

de Campos, M.C.R., S.J. Pearse, R.S. Oliveira, and H. Lambers. 2013. Downregulation of net phosphorus-uptake capacity is inversely related to leaf phosphorus-resorption proficiency in four species from a phosphorus-impoverished environment. Ann. Bot. (Lond.) 111:445-454.

Eschrich, W., J. Fromm, and S. Essiamah. 1988. Mineral partitioning in the phloem during autumn senescence of beech leaves. Trees (Berl.) 2:73-83.

Fernández-Escobar, R. 2008a. Fertilización, p. 297336. In: D. Barranco, R. Fernández-Escobar, and L. Rallo (eds.). El Cultivo del Olivo, 6th ed. Ediciones Mundi-Prensa, Madrid, Spain.

Fernández-Escobar, R. 2008b. Olive fertilization practices in the Mediterranean region. Olivae 109:13-22.

Fernández-Escobar, R., M.A. Sánchez-Zamora, J.M. García-Novelo, and C. Molina-Soria. 2015. Nutrient removal from olive trees by fruit yield and pruning. HortScience 50:1-5. M.A. Sánchez-Zamora, and C. Molina-Soria. 2014. The amount of nitrogen applied and nutritional status of olive plants affect nitrogen uptake efficiency. Sci. Hort. 167:1-4.

Fernández-Escobar, R., M. Guerreiro, M. Benlloch, and M. Benlloch-González. 2016. Symptoms of nutrient deficiencies in young olive trees and
Fernández-Escobar, R., M.F. Antonaya-Baena, leaf nutrient concentration at which such symptoms appear. Sci. Hort. 209:279-285.

Gilbert, N. 2009. The disappearing nutrient. Nature. 461:716-718.

Hartmann, H.T., K. Uriu, and O. Lilleland. 1966. Olive nutrition, p. 252-261. In: N.F. Childers (ed.). Temperate to tropical fruit nutrition. Horticultural Publications, Rutgers University, NJ.

Hartmann, H.T. and J.G. Brown. 1953. The effect of certain mineral deficiencies on the growth, leaf appearance, and mineral content of young olive trees. Hilgardia 22(3):119-130.

Holford, I.C.R. 1997. Soil phosphorus: Its measurements and its uptake by plants. Austral. J. Soil Res. 35(2):227-239.

Kisko, M., N. Bouain, A. Rouached, S.P. Choudhary, and H. Rouached. 2015. Molecular mechanisms of phosphate and zinc signaling crosstalk in plants: Phosphate and Zinc loading into root xylem in Arabidopsis. Environ. Exp. Bot. 114:57-64.

Kurita, Y., K. Baba, M. Ohnishi, A. Anegawa, C. Shichijo, K. Kosuge, H. Fukaki, and T. Mimura. 2014. Establishment of a shortened annual cycle system; a tool for the analysis of annual re-translocation of phosphorus in the deciduous woody plant (Populus alba L.). J. Plant Res. 127(4):545-551.

Marschner, H. 2012. Mineral nutrition of higher plants. 3rd ed. Academic Press, London, UK.

Murphy, J. and J.P. Riley. 1962. A modified single solution method for determination of phosphate in natural waters. Anal. Chim. Acta. 26(1):31-36.

Raghothama, K.G. 1999. Phosphate acquisition. Annu. Rev. Plant Physiol. Plant Mol. Biol. 50:665-693.

Rausch, C. and M. Bucher. 2002. Molecular mechanisms of phosphate transport in plants. Planta. 216:23-37.

Rennenberg, H. and C. Herschbach. 2013. Phosphorus nutrition of woody plants: Many questionsfew answers. Plant Biol. 15:785-788.

Restrepo-Diaz, H., M. Benlloch, and R. FernándezEscobar. 2008. Plant water stress and $\mathrm{K}+$ starvation reduce absorption of foliar applied K + by olive leaves. Sci. Hort. 116:409-413.

Safaya, N.M. 1976. Phosphorus-Zinc interaction in relation to absorption rates of phosphorus, zinc, copper, manganese and iron in corn. Soil Sci. Soc. Amer. J. 40(5):719-722.

Schachtman, D.P., R.J. Reid, and S.M. Ayling. 1998. Phosphorus uptake by plants: From soil to cell. Plant Physiol. 116:447-453.

Shane, M.W., M.E. McCully, and H. Lambers. 2004. Tissue and cellular phosphorus storage during development of phosphorus toxicity in Hakea prostate (Proteaceae). J. Expt. Bot. 55 (399): 1033-1044.

Shear, C.B. and M. Faust. 1980. Nutritional ranges in deciduous tree fruits and nuts. Hort. Rev. 2:142-163.

Shen, J., L. Yuan, J. Zhang, H. Li, Z. Bai, X. Chen, W. Zhang, and F. Zhang. 2011. Phosphorus dynamics: From soil to plant. Plant Physiol. 156:997-1005.

Smith, S.E. and D.J. Read. 2008. Mycorrhizal Symbiosis. 3rd ed. Elsevier/Academic Press, Amsterdam, The Netherlands.

Thornton, M.K., R.G. Novy, and J.C. Stark. 2014. Improving phosphorus use efficiency in the future. Amer. J. Potato Res. 91:175-179.

Vance, C.P., C. Uhde-Stone, and D.L. Allan. 2003. Phosphorus acquisition and use: Critical adaptations by plants for securing a nonrenewable resource. New Phytol. 157:423-447.

Weinbaum, S.A., R. Scott Johnson, and T.M. DeJong. 1992. Causes and consequences of overfertilization in orchards. HortTechnology 2:112-120.

Zeng, H., G. Wang, X. Hu, H. Wang, L. Du, and Y. Zhu. 2014. Role of microRNAs in plant responses to nutrient stress. Plant Soil. 374:1005-1021. 